\title{
Animal testing: There is no alternative
}

When scientists, animal advocates, and policy-makers gathered in Utrecht (the Netherlands) last month to discuss the three "Rs", they weren't talking reading (w)riting, and (a)rithmetic. Instead, replacement, reduction and refinement of animals used in research, product testing and vaccine production were the focus of the Second World Congress on Alternatives to Animal Testing (October 20-24). The semiannual Congress is one of the few places where one can witness a constructive dialogue between animal rights groups and cosmetic companies, as both try to eliminate the need for animal testing in the cosmetic industry.

In 1993, the European Union issued an edict aimed at banning the manufacture and marketing of ingredients tested in animals strictly for cosmetics. Because European consumers constitute the largest cosmetic market, buying more than one-third of the cosmetics sold in the world (the US comes in second at 30 percent), interna- tional cosmetic companies like L'Oreal and Procter \& Gamble are working to create ways to test the safety of a product without using an animal. However, alternative techniques must pass regulatory muster, which is proving to be the greatest obstacle to compliance with the pending ban.

Developing and validating effective alternatives "was more difficult than we had imagined," says Michael Balls, head of the European Centre for the Validation of Alternative Methods in Ispra, Italy. For example, in a study conducted by the European Cosmetic, Toiletry and Perfumery Association, ten different in vitro tests for eye irritancy failed to predict the eye irritation potential of 55 substances as reliably as the current regulatory standard, which requires the use of rabbits. Because of the difficulties in identifying alternatives to animal testing, the edict's loophole clause, which gives a two-year extension if "insufficient replacement methods exist," will likely be enacted.

Other areas in the spotlight at the Congress were refinement and biotechnology. Despite the fact that advances in transgenic animal technology are reducing the need for some forms of primate study (such as vaccine analysis), the biotechnology explosion may not have the effect sought by conference attendees. Albert Osterhaus, of Erasmus University in Rotterdam, the Netherlands, pointed out that although the new technologies will eventually decrease the number of animals used for biological product manufacturing and quality control, "it should be realized the the current revolution in molecular and immunological techniques also creates an explosion in new research and development activities. The introduction of novel products for new applications will cause an increased use of laboratory animals."

BARBARA NASTO New York, New York

\section{Big ISH, small pond}

It is as if one were issued a court citation by a local game warden for not having a license while standing with one's prize catch dangling from the tip of the fishing pole: Oncor, Inc., of Gaithersburg, Maryland, is bracing itself for what may become a nasty court battle. By not sublicensing from Vysis, Inc., of Downers Grove, Illinois, the rights to sell specific reagents to their commercial customers who use fluorescence in situ hybridization (FISH) technology, Oncor has drawn Vysis' ire. The controversy centers around a patent entitled, "Methods for chromosome-specific staining" for FISH, of which Vysis is the exclusive licensee from the University of California. The patent is also known as the Gray-Pinkel patent, as it is named after the inventors, Joseph Gray and Daniel Pinkel, who are professors at the University of California at the San Francisco Cancer Center.

Oncor believes the claims made in the Gray-Pinkel patent are invalid, as well as unenforceable. Oncor's director of intellectual property, Glen Karta, noted that the essence of the patent is the addition of blocking DNA to suppress hybridization of repetitive sequences from a DNA probe that contains both unique and repeat sequences, labeled in any manner. Karta further pointed out that such a procedure has been well documented and reduced to practice in, for example, autoradiographic and fluorescent hybridization assays well before the filing date of the Gray-Pinkel patent. Oncor is selling fluorescent-tagged unique human probes for genes associated with cancer and other human disorders.

Vysis, on the other hand, as the exclusive licensee of the patent, says it will vigorously protect its intellectual property. FISH, like the contested polymerase chain reaction (PCR), is widely used by both researchers and companies. The size of the "dangling FISH" market, which is currently divided between the clinical research and diag- nostic markets, is estimated to be between US $\$ 100$ and $\$ 200$ million. As with PCR, the FISH market could rapidly expand to over US\$1 billion in a few years, because it is easier, faster and cheaper than competing technologies.

Vysis contends that the Gray-Pinkel patent (filed in January 1986, and issued on 5 September 1996), is an invention that enables one to perform unique sequence staining of a gene on a specific chromosome. Vysis' president and CEO, John Bishop, pointed out that it wasn't until the discovery by Gray and Pinkel that FISH became broadly used by the scientific community. "FISH is an inventive and new technology that has evolved into a highly significant market opportunity. Our position is to make the technology broadly available in the market," said Bishop.

Vysis has also announced that they are requiring all laboratories performing FISH tests on a fee-for-service basis either to use reagents from a manufacturer with a sublicense, or to pay a royalty to Vysis on the fees being generated for performing the test. However, reflecting Vysis' "good will," the company will exempt research laboratories using the FISH technology from any sublicense agreements. Additionally, the company will waive any obligation to royalty payments with laboratories executing a sublicense agreement until the validity of the patents has been decided in court.

The FISH patent infringement case is expected to come to trial early next year in San Francisco in the Federal District Court of Northern California. Although it is difficult to predict the outcome, it will be interesting to see if the Patent Court swallows Oncor's arguments - hook, line and sinker - or if the company is just on an errant fishing expedition.

JOHN WONG Los Angeles, California 